\title{
A Critical Appraisal of the UK's Regulatory Regime for Combustible Façades
}

Judith Schulz and Darren Kent, Arup, 13 Fitzroy Street, London W1T 4BQ, $U K$

Tony Crimi, A.C. Consulting Solution Inc, 10660 Yonge St, Box 30613, Richmond Hill, ON L4C 4HO, Canada

Jim L. D. Glockling, Fire Protection Association, London Road, Moreton in Marsh, Gloucestershire GL56 ORH, UK

T. Richard Hull $\mathbb{D}$, Centre for Fire and Hazard Science, University of Central Lancashire, Preston PRI $2 \mathrm{HE}, \mathrm{UK}$

Received: 14 August 2018/Accepted: 8 May 2020

\begin{abstract}
The Grenfell Tower fire has brought the regulatory system that permitted combustible materials on high-rise buildings in England into question. At the heart of that system is the BS 8414 test, and the BR 135 criteria used to demonstrate compliance with the Building Regulations. The test is empirical and the criteria arbitrary: there is no scientific link between test performance and how a building will perform in the event of a fire; nor any detailed analysis of why fires spread through façade systems which have passed the test. Following the Grenfell tragedy, the UK government commissioned a series of tests on Grenfell Tower-type facades, using BS 8414. This paper critically analyses BS 8414 , the BR 135 criteria and the government tests. It shows that important aspects of the standard are poorly defined: the heat flux imposed on the façade is not measured and the fire load can vary by at least a factor of 2; the ambient ventilation has a significant impact on the thermal attack but is not adequately controlled; judicious location of the cavity barriers can confer compliance or failure on a façade system. As the vehicle for allowing combustible products on tall buildings, the test does not specify the extent of cavity barrier deployment, while ignoring features present in real buildings, such as windows, vents or other openings, despite a test rig height of more than $8 \mathrm{~m}$. There is no restriction on debris, or molten or burning droplets falling from the façade during the test. The BR 135 criteria only specify that the test must run for the full $60 \mathrm{~min}$ duration without flames reaching the top, and the temperature rise at thermocouples $5 \mathrm{~m}$ above the fire chamber must only remain below $600^{\circ} \mathrm{C}$ for the first $15 \mathrm{~min}$. It is unclear how the fire safety of the occupants behind the façade system can be ensured, when the criteria specify such a high temperature for such a short period, so early in the test. There is no direct connection between the façade system in the test and the actual façade system the results deem compliant. Worse, "desktop studies", using large-scale test data, have been allowed to confer compliance on systems which have never been subject to the test. The UK government tests used heavy-duty welded aluminium "window pods", preventing flames from entering the cavity within the façade. They also used a dis-
\end{abstract}

\footnotetext{
*Correspondence should be addressed to: T. Richard Hull, E-mail: trhull@uclan.ac.uk
} 
proportionately large number of vertical and horizontal cavity barriers of a higher specification than required by statutory guidance. These aids to meeting the criteria are not proscribed by BS 8414-1 but are not commonly found in actual rainscreen system designs.

Keywords: Facade, regulation, BS 8414, combustible, testing, fire

\section{Introduction}

The fire that destroyed the Grenfell Tower and took 72 lives, in London in June 2017, spread rapidly around an external, combustible rainscreen façade system [1, 2].

Following that tragedy, the UK's existing multi-storey housing is in crisis because of the uncertainties around their fire safety: it is no longer clear which combinations of which façade products are compliant with the UK building regulations [3]. An ongoing government survey of façades of high-rise residential buildings in both the private and public sectors identified 454 buildings taller than $18 \mathrm{~m}$ that were known to have highly combustible aluminium composite material (ACM) on the external walls. To date, 114 have completed the remediation works and are considered likely to meet Building Regulations [3]. Buildings, similar to Lakanal House (a London tower block where six people died in a fire in 2009), which have combustible high-pressure laminate (HPL) panels (wood-fibre bound with a phenol-formaldehyde resin); timber-clad buildings; or the large number of multi-storey buildings with combustible foam insulation, faced with a thin render of fibre reinforced cement (External Thermal Insulation Composite Systems, ETICS), in the place of ACM, have yet to be considered. The UK government [4] estimated that 600 high-rise buildings with combustible façades need to be approved each year.

The UK's regulatory framework for fire safety of buildings is performancebased. For example, in England, Schedule 1 of the Building Regulations (2010), Section B4 (1), covering prevention of external fire spread, states, "the external walls of the building shall adequately resist the spread of fire over the walls and from one building to another, having regard to the height, use and position of the building". Photographs and video footage demonstrate that the walls of Grenfell Tower did not resist the spread of fire; and has now been found to not comply with this regulation [5].

However, guidance as to how this performance-based regulation may be met is given in the UK government's 180 page Fire Safety: Approved Document B [6] (AD B). AD B explains that this can be achieved by the use of non-combustible products on the outside walls of the building, or by meeting certain criteria based on large-scale test results. It can also be met through the use of fire safety engineering. 


\subsection{Different Scales of Test}

Non-combustibility is typically assessed on a microgram to gram-scale, for example, by rapid oxidation in a bomb calorimeter, in 25 bar of oxygen, or a non-combustibility apparatus (EN ISO 1182) which employs a cylindrical specimen of diameter $45 \mathrm{~mm}$ and height of $50 \mathrm{~mm}$ by observing flaming or quantifying temperature rise in a furnace at $750^{\circ} \mathrm{C}$. These tests are robust in that they will ensure that any material which could burn in a fire will not meet the non-combustibility requirement. They are also quick and cheap to run, with excellent interlaboratory reproducibility.

Bench-scale tests usually involve flaming combustion, typically burning under a controlled set of conditions at a fixed heat flux, while continuously recording data on heat release and burning behaviour. These are most widely used for material development, and to provide input of burning behaviour in models of large-scale fires [7]. They are also used for regulatory testing. While showing lower repeatability and reproducibility than the micro- or gram-scale tests, their reproducibility is greater than that of large-scale tests, and much more information is available from a heat release curve than a single pass/fail result. In the UK, an alternative to the Euroclass B criteria [8] for flammability of façade products was the UK class O. This required a pass in BS 476 part 6 and Class 1 performance in part 7 . Both tests clamp a flat sample, of $0.05 \mathrm{~m}^{2}$ and $0.25 \mathrm{~m}^{2}$ respectively, in a non-combustible holder, and expose it to a radiative heat flux, and pilot ignition source. When materials such as the polyethylene-filled aluminium composite panels, that drove the rapid fire spread on Grenfell Tower are tested, since the aluminium panel face is non-combustible, if the polyethylene is able to drip away from the flame entirely, it will meet the test criteria; if it flows into the flame it will ignite and fail. Indeed, it could be argued that the popularity of aluminium composite panels in the UK was linked to the test regime in place-while losing sight of the real fire performance of the product.

The single burning item (SBI) test (EN 13823), designed for Euroclassification of internal wall-lining products, is an intermediate scale test. A $30 \mathrm{~kW}$ propane burner is situated in an internal corner of two faces of product, $1.5 \mathrm{~m}$ high and $1 \mathrm{~m}$ and $0.5 \mathrm{~m}$ wide. It covers classifications from A2 to D, based on the fire growth rate (FIGRA), the total heat release during minute 5 to minute 15 of the test $\left(\mathrm{THR}_{600}\right)$ and the maximum flame spread. Additional classifications cover smoke (SMOGRA), total smoke production during minute 5 to minute 15 of the test $\left(\mathrm{TSP}_{600}\right)$ and burning droplets/particles. Although the SBI is a smaller scale, it could be argued that it is more robust than some larger scale tests, in that classification depends on three replicate tests meeting defined thresholds in quantitative heat release and flame spread data. It has been used to assess the fire performance of external products such as façade panels, tested as individual components. Before the Grenfell Tower fire, polyethylene-filled aluminium composite panels were reported to have met Euroclass B, but after the fire, through the system of notified bodies, other test laboratories found the same product only achieved Euroclass $\mathrm{C}$ and $\mathrm{D}$ in their tests, so the original certificate was withdrawn. There 
are many other intermediate scale tests for wall-lining and façade products, including the $2.4 \mathrm{~m}$ tall ISO $13785-1$ test.

Large-scale tests have the potential advantages of involving larger ignition sources, have a larger area of façade, and hence fuel, to involve in a potential conflagration, and can reduce the scale differences of products manufactured for large façades (e.g. insulation boards $150 \mathrm{~mm}$ thick, or ACM with $0.5 \mathrm{~mm}$ aluminium sheet sandwiching $3 \mathrm{~mm}$ of polyethylene). They claim to be more representative of the real fire scenario (such as a façade fire ignited by a post-flashover apartment or burning rubbish skip). These tests are the focus of this paper.

\subsection{The UK Combustibles Ban}

In December 2018, an additional requirement was added to the Building Regulations for England, which control the presence of combustible materials on the external walls of certain buildings with a storey above a height of $18 \mathrm{~m}$. These include residential blocks of flats, student accommodation, care homes, sheltered housing, hospitals, and dormitories in boarding schools, but not hotels or offices. However, the ban is not retrospective, and only applies to properties built or refurbished after February 2019, and those undergoing a change of use (i.e. those buildings that become residential, and institutional buildings where previously they were not). The amended regulations are currently under review, [9] so the topic is particularly pertinent to the fire safety of tall residential buildings in the UK.

\subsection{Regulations for Tall Buildings not Covered by the Ban}

For external wall construction of buildings over $18 \mathrm{~m}$ not captured by the new regulation, the latest edition of $\mathrm{AD} B$ specifies the use of insulation of Euroclass A2 or better, and external wall surface classification of Euroclass B, or better (known as "the direct route to compliance"). Alternatively, a façade system that satisfies the criteria of BR 135 following a large-scale façade fire test carried out as specified in BS 8414 is also deemed acceptable. BS 8414 describes a pair of large-scale tests, between 8 and $9 \mathrm{~m}$ tall, involving a developed fire impinging on the external face of a façade system which incorporates an internal corner. The 2006 edition of AD B and the 2019 edition covering non-residential buildings provide a route for compliance with the Building Regulations by meeting the performance criteria given in BR 135 for external walls using full-scale test data from BS 8414-1 or BS 8414-2. The phrase "test data", allows "desktop studies" to be used where the large-scale test result for that façade system is not available. This has led to widespread criticism of the England's fire safety regulations. BS 8414 was developed by BRE in response to real façade fires. In BS 8414-1 [10], the internal corner is made by two fire resistant masonry walls on which the façade system under test is installed. Such façades are often used for refurbishment of existing, concrete-walled buildings. BS 8414-2 [11] uses a steel framework lined by plasterboard on the inside, onto which a wall corner system is mounted: this test relates to more modern, steel-framed constructions. 
$B R$ 135: Fire Performance of external thermal insulation for walls of multistorey buildings [12], is a document written by BRE Global (now a private company, but until 1997 was the UK government's Building Research Establishment). Annex A and B: performance criteria and classification method for BS 8414-1 and BS 8414-2 set out criteria to determine whether a particular façade system meets the UK building regulations, based on the results of testing according to the BS 8414 standard. The BS 8414 test and the criteria in BR 135 are the route which allows combustible materials to be used in the construction of external walls of high-rise buildings. The construction of the façade is the responsibility of the test sponsor, who also provides a description of the façade system for the classification report. The results of a BS 8414 test should be documented in a fire test report, for a specific façade system. In the UK, these results are then compared to the criteria of BR 135, and if they have been met, a separate BR 135 classification report is issued for that façade system. In addition, variants of BS 8414 are used in Australia, Belgium, China, United Arab Emirates and Ireland. A derivative of the test is currently undergoing evaluation by the European Commission as the façade test to be adopted within the Construction Products Regulation [13].

\subsection{Facade Fires and their Relationship to Large-Scale Fire Tests}

Façade fires are of great interest to the fire safety community, internationally. As early as 1996, Babrauskas [14] warned of "the very serious consequences that can result when fire does propagate over the façade of a high-rise building". More recently, the editorial [15] of a special issue of this journal (Fire Technology), on the fire safety of high-rise buildings highlighted the extensive use of external façade insulation materials bringing new fire safety issues. A year later the editorial of a special edition of Fire and Materials [16] also highlighted the number of recent incidents which involve extensive façade fires.

Following the Grenfell Tower fire, Babrauskas [17] argued strongly for the need for science to underpin large-scale fire tests used to ensure the fire safety of building façades. Apart from a handful of micro- and bench-scale tests for assessing heats of combustion, these are purely empirical and hence the results are only valid for the test scenario itself. Babrauskas pointed out that numerous studies of façade fire disasters have been written, but none had been related to the tests used to allow the façade system in the first place. In a detailed consideration of façade fires, Bonner and Rein [18] argue that if an engineering "flammability index" existed for façades, they could be better optimised to meet both fire safety and thermal insulation criteria. The "flammability index" concept has subsequently been developed, using a database of over 250 Polish tests, on rainscreen, ETICS and sandwich panel façades, providing information on the fire performance of different types of façade product and design [19].

\subsection{Other Facade Tests}

The European Construction Products Directive and subsequently Regulations (CPR) [20] aimed to eliminate barriers to trade across Europe through a harmonised system of performance testing of construction products. They have been 
operational for over 20 years. In assessing fire performance, they use somewhat different test protocols for different product classes. Despite façade products being recognised as a separate product class since the CPR's inception, only recently have façade test methods been proposed for incorporation into the European system. A European Commission (EC) funded study has recently been published [21] on means to regulate the fire performance of façade systems. They identify a lack of scientific data relating to key performance characteristics, such as heat exposure of the test specimen for the various test methods; whether tests are conducted outside or within laboratory buildings; and acknowledge the trade-off between the range of applications represented by a particular test result and the test burden needed to cover a wider range. In addition to the intermediate-scale SBI test, they identify around 10 larger scale test methods used by member states to assess the fire performance of façade systems. Since the EC are currently considering use of the BS 8414, alongside DIN 4102-20 test, the discussion in this paper is particularly timely.

There are several large-scale fire façade tests in use globally. The most important have been compared in Table 1, showing the key parameters. All the façade tests shown in the table relate to a scenario in which flames emerge from a postflashover compartment onto the façade, originating from a single fire source, except NFPA 285, which uses two fire sources. ISO 13785, BS 8414, and DIN 4102-20 all have two walls in an internal L-shape, while NFPA 285 and SP FIRE 105 have a single wall. In addition, SP FIRE 105 also has a "fictitious" window opening above the fire compartment.

Anderson et al. [22] compared the fuel source in BS 8141-1 and the Nordic façade test, SP Fire 105. While BS 8141-1 uses a volume of wood, SP Fire 105 uses a volume of heptane. In SP 105 the heat flux is measured and used for control, in BS 8414 the heat exposure to the façade surface is uncontrolled, and it may differ from test to test due to factors such as timber variation and air movements around the combustion chamber. They showed that air movements around the test set-up (the wind) had a significant impact on either test.

The aim of this paper is to provide an assessment of the current test method, BS 8414, the criteria for compliance in BR 135, and of the post-Grenfell UK government tests.

\section{The BS 8414-1 Façade Test}

Early research into the UK's regime for large scale façade testing was undertaken by the Fire Research Station, now part of BRE, in 1994 [23]. The original testing regime proposed in 1994 incorporates many features which have been omitted from the BS 8414 tests. It was 4 storeys tall, with a combustion chamber at the base, and 3 window openings on the storeys above. The top detail of the combustion chamber was identical to the top of the window openings. The power output was quantified as a function of time, through the mass loss of the wood crib, and heat flux was measured $1 \mathrm{~m}$ above the combustion chamber and at the first-floor window. The failure criteria included reaching a temperature of $400^{\circ} \mathrm{C}$, rather 


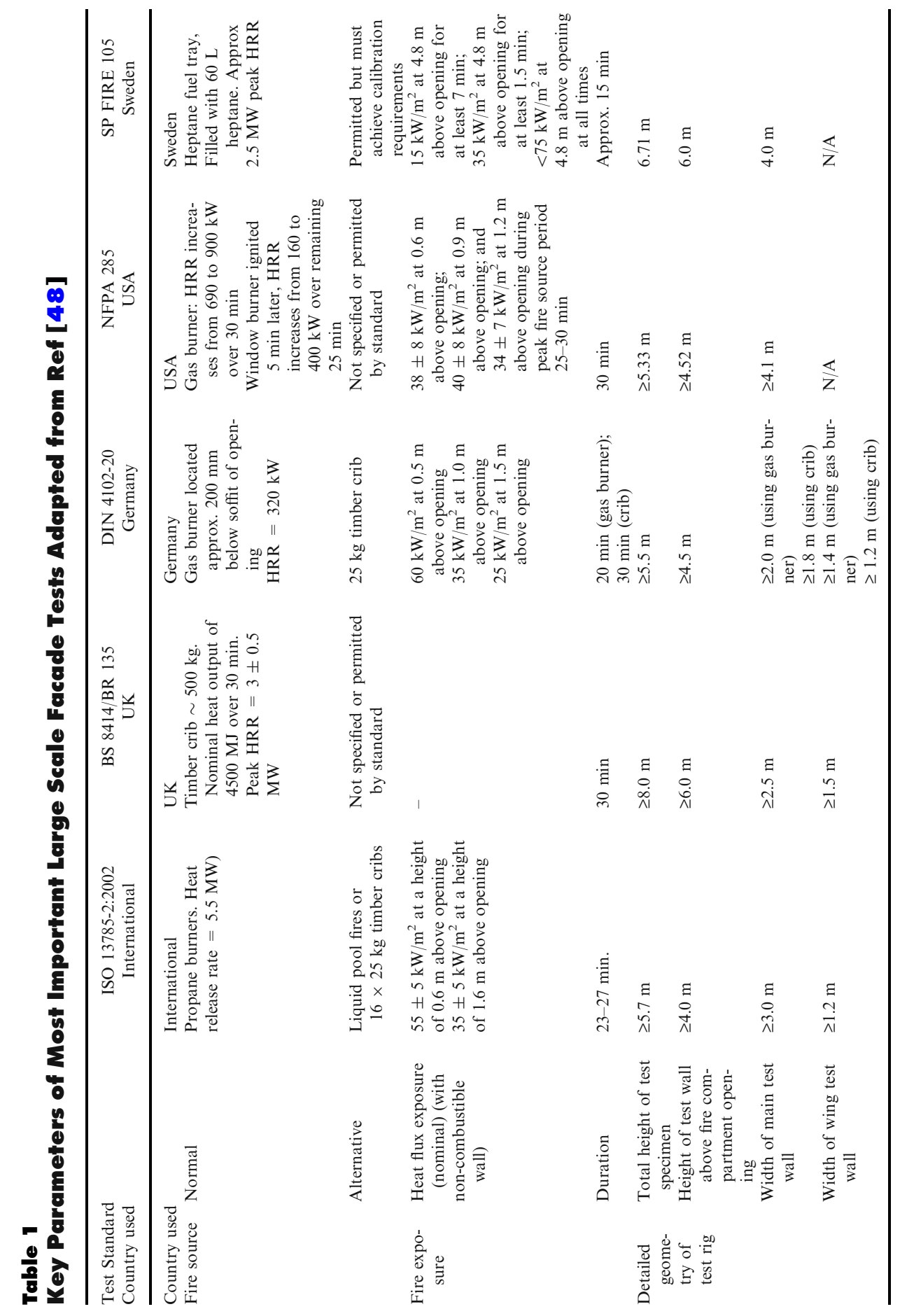




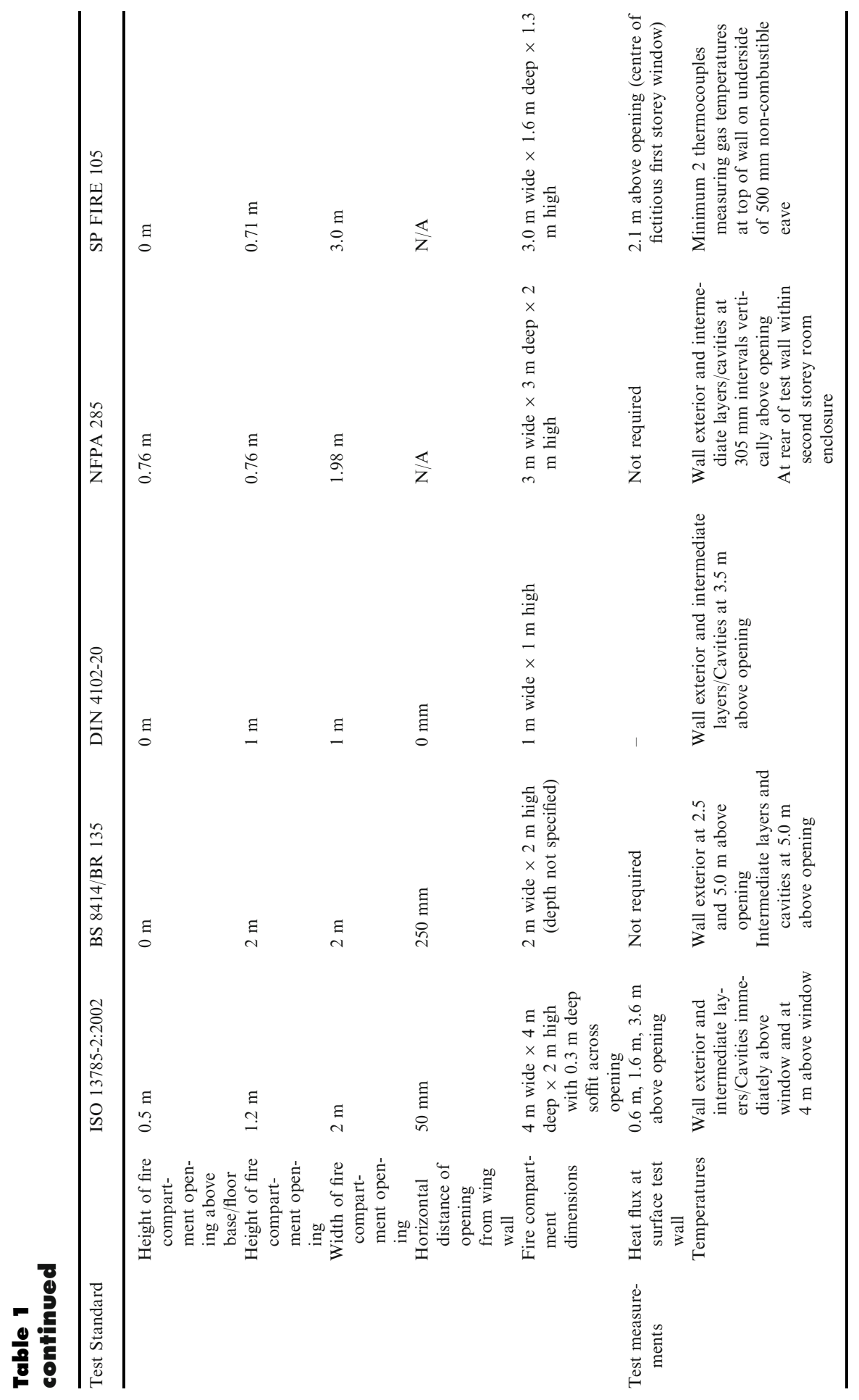




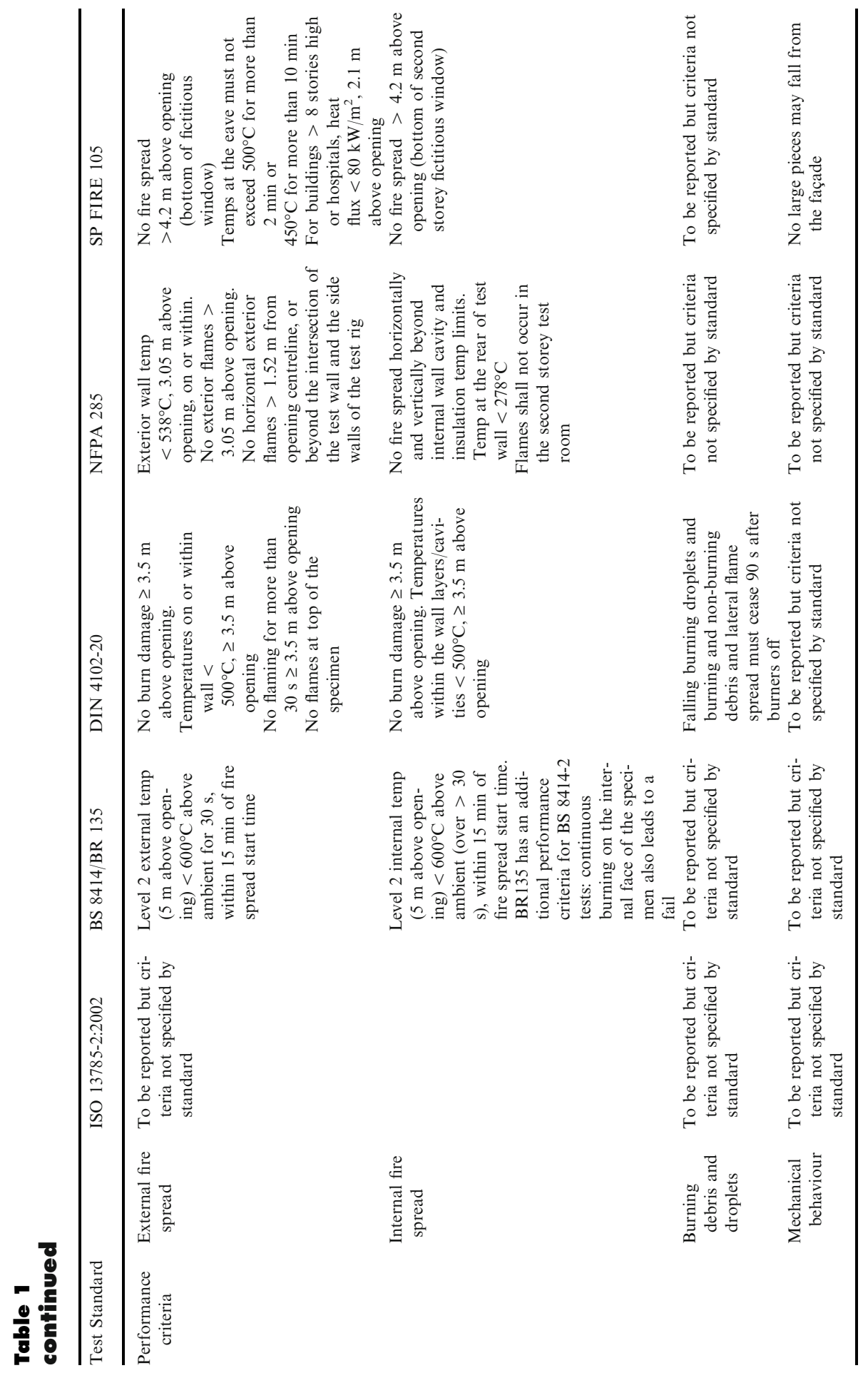


than the $600^{\circ} \mathrm{C}$ of the current test, flames reaching the second floor, and debris falling from the façade. The following statement appeared in the summary. "In assessing the fire hazard, it was found that the design, detailing and construction of the complete cladding system is more important than the reaction to fire properties of the individual materials involved. Consequently, it is suggested that the fire hazard be determined by testing the complete cladding system as in practice." Unfortunately, this rigorous test protocol has lost many of its key features in the development of the current BS 8414 tests.

Figure 1 shows the current, BS 8414-1 test set up, dimensions and location of thermocouples. The test rig consists of a main face (masonry wall), with an aperture for the combustion chamber, adjoining a wing (second masonry wall) forming an internal corner. The façade system is attached to the walls, leaving an opening in front of the combustion chamber. The standard lacks specificity in key areas.

The post-flashover room with flames billowing out of the window onto the façade in a real building is replicated by the combustion chamber in the test. In stark contrast to the original 1994 façade test protocol, the standard now states that "the combustion chamber shall be capable of enduring the effects of the test procedure without itself suffering undue damage or distortion." Only the internal dimensions are specified. For the test to be representative of a real building (with windows), the resilience of the fitting around the combustion chamber in the façade must match the detail of the cladding system actually used in the real building. Any deficiencies around the window of a real building, which may be masked by decorator's finishings, could allow flames to penetrate the cavity earlier. If the cavity is lined with combustible insulation, breather membranes, and cladding, the fire performance will be very much worse. Thus, an unrealistically robust window detail around the combustion chamber in the test could lead to significant variation between test performance, and fire behaviour in a real building with a less robust detail.

BS 8414 specifies thermocouples at level 1 and 2, Fig. 1, located at mid-depth of the insulation, at the mid-depth of the cavity, and protruding $50 \pm 5 \mathrm{~mm}$ outside the external face. BS 8414-1 does not specify whether or where cavity barriers (fire stopping) should be used, although their use is implied by the requirement to report any failure of such a barrier during the test.

The distances to the thermocouples on the first and second level of $2.5 \mathrm{~m}$ and $5.0 \mathrm{~m}$ above the combustion chamber are not reflective of actual building floor to floor heights, which are usually in the range of $2.7 \mathrm{~m}$ to $3.3 \mathrm{~m}$. This means that either the façade design is modified such that the cladding panels are made shorter than would normally be used in practice, so that the second set of thermocouples remain above the cavity barrier, which would normally be at second floor level, or that the thermocouples are located within the cavity of the first floor, where they are more likely to reach failure temperature.

The most important is the difference between the test construction and the use of the test result to confirm compliance on non-identical systems, in real buildings. Statements, such as the NHBC Guidance [24] that polyethylene-filled ACM with certain PIR or phenolic foam insulation products, or the UK government tests 


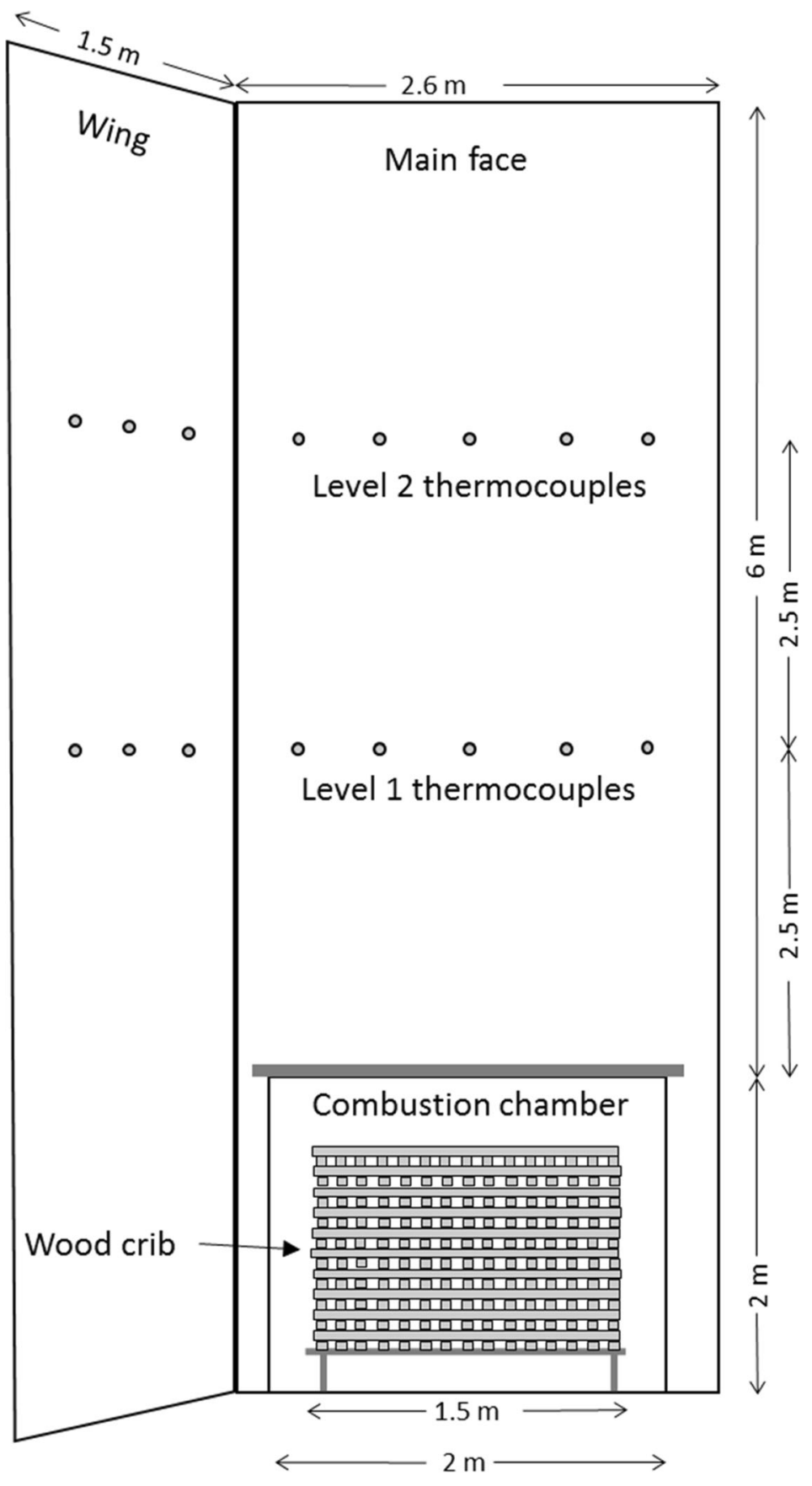

Figure 1. Test set up including thermocouple location. 
showing that ACM with a non-combustible filling in front of PIR foam [25] meet the requirements set out in AD B ignore the importance of the construction detail. BR135 states that "the classification applies only to the system as tested and detailed in the classification report. The classification report can only cover the details of the system as tested. This statement was used in Dr Barbara Lane's expert witness report to the Grenfell Tower Inquiry who concluded that "any difference between the Grenfell Tower rainscreen cladding system and the relevant supporting fire test evidence when classified with BR135 means the test evidence cannot be relied on to demonstrate compliance..."

\subsection{Fire Source and Fuel Load}

The fire load in BS 8414 is defined by the quantity of timber used to build the crib. It is nominally $4500 \mathrm{MJ}$, with peak heat release rate $3.0 \pm 0.5 \mathrm{MW}$. This is less than the ISO $13785-2$ test, and less than many post-flashover room fires. The test time starts when the heat reaching the façade causes a temperature rise of $200^{\circ} \mathrm{C}$, at level 1 . It is allowed to burn for $30 \mathrm{~min}$, then the crib is extinguished, but the façade may continue to burn. After the crib is extinguished a significant amount of charred timber remains. However, there is no requirement to calibrate or quantify either the fuel load or the heat release rate. Further, there is no attempt to quantify the incident heat flux on the façade. No rationale is provided for extinguishing the crib after $30 \mathrm{~min}$.

The tolerances specified in Annex A of BS 8414-1, describing the timber crib source, allow a minimum and maximum mass of timber and heat release to be calculated. Annex A specifies the crib as 100 sticks of $50 \pm 2 \mathrm{~mm} \times 50 \pm 2 \mathrm{~mm}$ square section and length $1500 \pm 5 \mathrm{~mm}$ and 150 sticks also of $(50 \pm 2 \mathrm{~mm})^{2}$ and of length $1000 \pm 5 \mathrm{~mm}$ of pinus sylvestris (Scots pine), of density 0.4 to $0.65 \mathrm{~kg} \mathrm{dm}^{-3}$ and moisture content $10 \%$ to $15 \%$. This gives a mass of timber of $394 \mathrm{~kg}$ (or $344 \mathrm{~kg}$ dry weight). However, if all the lower limits are used, a minimum mass of timber of $277 \mathrm{~kg}$ (or $236 \mathrm{~kg}$ dry weight) is specified, while the upper limit is $529 \mathrm{~kg}$ (or $476 \mathrm{~kg}$ dry weight). Taking into account the energy required to heat $\left(\mathrm{C}_{\mathrm{P}}\right)$ and vaporize $\left(\Delta \mathrm{H}_{\mathrm{vap}}\right)$ the water content, and a heat of combustion of dry pinus sylvestris of $19.31 \mathrm{MJ} \mathrm{kg}^{-1}$, this gives a lower total heat release of $4529 \mathrm{MJ}$ and an upper value of $9169 \mathrm{MJ}$. This shows that precise specification of timber can halve the energy available for the thermal attack on the façade. This adds an additional layer of uncertainty to test results.

\subsection{The Effects of Ventilation and Wind}

Recent research published in Sweden by RISE [26] notes that "experimental results [...] showed that the fire exposure on the façade varies in BS 8141-1 [...]. This means that it is not possible to control the fire exposure on the façade surface, and it may differ from test to test due to factors such as air movement around the combustion chamber and the geometry of the façade system". The only indicator of fire exposure on the façade comes from the thermocouples, particularly those at level 1 . In BS 8414, the level 1 thermocouples are used to establish two test parameters $T_{s}$ and $t_{s}$. $T_{\mathrm{s}}$ is the start temperature, defined as the 
average temperature $5 \mathrm{~min}$ before ignition. $t_{\mathrm{s}}$ is the start time, which is set as zero when the temperature rise exceeds $200^{\circ} \mathrm{C}$ on any of the level 1 thermocouples, provided they do so for at least $30 \mathrm{~s}$.

\subsection{Panel Joints}

In a façade system, panel joints provide greater susceptibility to attack from fire. BS 8414-1 specifies that vertical joints should be within $100 \mathrm{~mm}$ of the centreline of the combustion chamber, where the heat flux is likely to be greatest. However, it also specifies that at least one horizontal joint shall be located $2.4 \mathrm{~m}$ above the combustion chamber opening. This is around the height of the level 1 thermocouples. Although the distance from the top of a window to the first horizontal joint in the cladding above it varies, it would not be uncommon for a joint to be located within a zone that is $1 \mathrm{~m}$ or $1.5 \mathrm{~m}$ above a window, causing the thermal attack on the façade to be more severe.

\subsection{Test Construction}

BS 8414-1 describes the test set-up "with the cladding system attached in the manner specified by the test sponsor." There are a variety of different panel types and panel support options for designers and fabricators to choose from, all of which can be considered common. Rainscreen panels can be flat and face-fixed to support rails or they can be folded around their edges and formed into "cassettes" which are "hooked onto" the support rails. The design of the panel support system is a function of several factors including the panel type, size, thickness and wind load. For "cassette" type panels, the interval between fixing positions at the supporting rails can be as large as $\sim 1500 \mathrm{~mm}$.

The test sponsor is most often the product manufacturer, whose interest comes from their desire to test an assembly, using their materials, that will successfully meet the acceptance criteria. Once accomplished, they are not in an objective position to assess variations from what was actually tested. They may also have significant know-how to use the design detail of the façade to optimise its performance in a test, which might deviate from normal practice on a construction site. Façade test construction is undertaken by skilled technicians, usually working for the product manufacturer, in ideal conditions, and to very different objectives and timescales to those employed on a construction site. The standard does not specify whether the test laboratory is obliged to observe and monitor the construction. There does not appear to be any requirement for the test laboratory to provide information on any of the design details.

\subsection{Design Detail}

The standard specifies only minimum dimensions of wall height and width. It is not specified in BS 8414 whether the detail at the top of the wall should represent an intermediate floor, or the top of the building. This is significant because the installation of cladding systems at the top of a wall can differ substantially from that between adjacent storeys. Complex details, e.g. where windows and vents 
need to be fitted into the cladding, and where drainage is provided from the ventilated cavity, critically affect fire performance. Their absence shows that the test is not aimed at replicating an idealized form of reality, but is somewhere between a component test and a system test for the part of the façade being tested.

\subsection{Cavities}

Babrauskas [17] described the discovery in Sweden in 1939, named the Schlyter effect, of fire growth in cavities within combustible panel systems (sometimes described as a "chimney effect" today). This effect has been subsequently rediscovered and quantified [27]. For polyurethane foam insulation and gypsum board, they found a cavity width of $25 \mathrm{~mm}$ limited the flame spread to $1-2 \mathrm{~m}$ in the configuration they used, while a width of $40 \mathrm{~mm}$ allowed flame spread through the test façade. For expanded and extruded polystyrene (EPS and XPS) and gypsum board, melting of the polystyrene widened the cavity so no such correlation was found. A cavity width of $50 \mathrm{~mm}$, with a polyurethane based foam, such as that used on Grenfell Tower and in the DCLG tests, may be close to the worst case for upward fire spread, while fire may have limited penetration of cavities narrower than $25 \mathrm{~mm}$; though further research is required here to establish robust correlations. This emphasises the need to test the façade system as constructed, with even non-combustible elements such as the cavity playing a critical role. The strong influence of the chimney effect in rainscreen type systems underpins the need for cavity barriers. The issue of fires within cavities is beginning to be modelled, for example using Fire Dynamics Simulator [28], and compared to experimental observations, in order to develop design approaches for these types of fires, which are not yet well understood.

\subsection{Application of BS 8414 Performance to Façade Design}

The dimensional constraints placed on the BS 8414 test present designers of the test specimens with a dilemma. It is not possible to "map" a real façade geometry onto the BS 8414 rig. Therefore, a test designer has to choose between two approaches:

1. Adjust the panel sizes and vertical dimensions of the test specimen to correspond to the positions of the thermocouples defined in BS 8414, so that the cavity barrier sits below the thermocouples. Thus, a level 1 thermocouple would represent the temperature of the floor above the combustion chamber and the level 2 thermocouples the temperature two floors above.

OR

2. Maintain representative panel sizes and vertical dimensions for the test specimen (as representative of typical arrangement on a real building), without consideration of the position of the thermocouples specified in BS 8414. This means that the level 2 thermocouples will sit below the cavity barrier corresponding to two floors above the combustion chamber. This would significantly increase the chance of test failure. 
Neither of the above approaches is satisfactory with respect to representation of typical cladding systems when applied to real buildings. It seems the first approach is often adopted, presumably as the designers of test specimens prefer the favourable arrangement for testing whereby the relative positions of cavity barriers and thermocouples are considered more important with respect to vertical fire spread, given that the temperature reading at level 2 will determine whether the test will pass or fail.

\section{The BR 135 Criteria}

"Annex A" of BR 135 provides the performance criteria in the BS 8414-1 test for compliance with the UK building regulations for tall, non-residential buildings such as offices and hotels. The first criterion is that "the system must have been tested to the full test-duration requirements of BS 8414-1 without any early termination of the full fire-load exposure period." BS 8414 requires termination of the test if flames extend beyond the top of the test rig. Thus, the façade system will automatically fail if flames are seen above the test rig during the test. However, as there is no maximum height of the rig prescribed, those testing in a taller test facility with a taller sample will be less likely to fail compared to those using a test sample of minimum height.

The main criterion stated in BR 135 is failure due to external or internal fire spread, which is deemed to have occurred if the temperature rise above $T_{s}$ of any of the thermocouples at level 2 exceeds $600^{\circ} \mathrm{C}$ for a period of at least $30 \mathrm{~s}$, within $15 \mathrm{~min}$ of the start time, $t_{s}$. The failure is reported as external or internal fire spread, based on the thermocouples affected. In terms of ensuring the prevention of internal or external fire spread within the façade there are two significant concerns with a temperature rise as large as $600^{\circ} \mathrm{C}$, over such a short duration. First, the majority of widely used polymeric construction materials will ignite below $500^{\circ} \mathrm{C}$, especially if a pilot flame is present. Items such as window frames and surrounds or vents, which are not included in the test, would be burning if there was a fire in a real building. This could result in a breach of the compartmentation to the floor above, before the temperature, $5 \mathrm{~m}$ (almost two storeys) above the combustion chamber, had risen by $600^{\circ} \mathrm{C}$. Second, $15 \mathrm{~min}$ is an unrealistically short fire exposure time: a fire in an apartment or waste container will burn for longer than this, and it is too short for effective firefighting on a tall building [29]. Since the test duration is $60 \mathrm{~min}$, if the purpose of the test is to ensure life safety, it seems unjustifiable for the critical safety parameter of facade fire spread, which is the rationale for the test, to be disregarded for the remaining $45 \mathrm{~min}$.

BS 8414-1 requires that "the times of significant events such as the change of flaming conditions and any change in the mechanical behaviour of the cladding system shall be recorded, especially the detachment of any part of the cladding system (whether flaming or otherwise) or any fire penetrations through fire stops incorporated within the cladding system." However, these test observations are not included in the BR 135 criteria. Falling debris and burning droplets present an additional hazard, for firefighters and emergency personnel, as well as people 
evacuating the burning building, or nearby. Burning droplets can also cause secondary ignition, making firefighting more difficult. BR 135 states that "mechanical performance" needs to be considered during risk assessment when the façade tested to BS 8414 is to be applied to a real high-rise building. The failure of cavity barriers should be observed during a BS 8414-1 test. However, it is not clear how either piece of information in the report is made available to risk engineers or end users, since there is no obligation for the manufacturer to make their test report public.

\section{The UK Government Sponsored Tests}

Two months after the Grenfell Tower fire, the UK government's Department of Communities and Local Government, now the Ministry of Housing, Communities and Local Government (MHCLG), asked BRE to undertake a series of tests on insulated rainscreen façade systems faced with ACM using the BS 8414-1 test, to "help building owners make decisions on any further measures that may need to be put in place [30]."

These tests are included because detailed test reports have been published, providing further insight into the regulatory process. The particulars of the design of the MHCLG sponsored tests, conducted between July and August 2017, are presented in the introduction of each of the 7 BRE test reports [31], stating "The design of the cladding systems have been reviewed by The Independent Expert Advisory panel and other industry bodies to ensure that they are representative of the systems that are in common use on buildings including the way they are fixed."

\subsection{Design Detail}

Each MHCLG test report [31] includes the description "a pre-fabricated, welded window pod constructed from $5 \mathrm{~mm}$-thick aluminium was fixed onto the edge of the combustion chamber opening... The window pod extended $180 \mathrm{~mm}$ perpendicular to the masonry wall so that it extended approximately $30 \mathrm{~mm}$ beyond the front face of the finished cladding system." The use of such heavy gauge "window pods" is not representative of typical construction detailing around windows. The protrusion by $30 \mathrm{~mm}$ of a $5 \mathrm{~mm}$ thick aluminium plate around the opening provides greater protection to the façade, and especially the cavity, than a typical window fitting. Since fire penetration into the cavity is one of the main hazards being assessed, this large shield and heatsink would effectively protect the lower part of the façade system, and particularly the vulnerability to fire attack above the window openings and into the cavity, by acting as a solid cavity barrier. Thus, a crucial aspect of façade fire safety not covered by these government tests is fire entry via the window openings and the perimeter interface around window openings into the cavity. 


\subsection{Effect of Ventilation on Fire Growth}

There are two BS 8414 test apparatuses located in the burn hall at BRE, known as test wall 1 and test wall 2 . In the tests commissioned by MHCLG at BRE, the publicly available test reports, show notable differences between the early fire growth rates from the wooden cribs with faster fire growth occurring consistently on test wall 2. A similar effect was reported from the RISE/Zagreb tests [26, 32], when run outside on days with different wind speeds.

Table 2 shows significant variation in the time taken from $t_{\mathrm{s}}$ for the temperature to reach $300^{\circ} \mathrm{C}$ at level 2. At this low temperature rise and short exposure time, the façade products have not contributed to the temperature rise, so the variation results only from the fire growth rate of the burning cribs. The second and third columns show this time for the level 2 thermocouples in the MHCLG tests [31]. This shows both a random variation, and a systematic difference between the fire growth rates, with test wall 2 reaching $300^{\circ} \mathrm{C}$ in half the time, on average. If such variation occurs in the same burn hall of a single test laboratory with the test walls alternated in sequence, it raises questions about the intra- and inter-laboratory reproducibility of the Standard. It may be that the two test walls are subject to different environmental ventilation, although there is a requirement in BS 8414 that the air velocity at the start of the test, at level 2, should be less than $2 \pm 0.5 \mathrm{~m} \mathrm{~s}^{-1}$. The UK government reports do not include air velocity data. The fourth and fifth columns of Table 2 show the time taken for the temperature to reach $300^{\circ} \mathrm{C}$ in the tests undertaken by RISE in Zagreb [26, 32]. The test wall was located outside, with the first three tests being conducted in spring, with a wind speed between $2 \mathrm{~m} \mathrm{~s}^{-1}$ and $5 \mathrm{~m} \mathrm{~s}^{-1}$ and the last three tests in summer, with

\section{Table 2}

\section{Time to Reach $300^{\circ} \mathrm{C}$ in UK Government Tests [3 1 ] and in RISE Tests [26]}

\begin{tabular}{|c|c|c|c|c|}
\hline \multirow[b]{3}{*}{ Test number } & \multicolumn{4}{|c|}{ Time to reach $300^{\circ} \mathrm{C}$ at Level 2 Thermocouples } \\
\hline & \multicolumn{2}{|c|}{ MHCLG tests } & \multicolumn{2}{|c|}{ RISE/Zagreb tests* } \\
\hline & Test Wall 1 & Test Wall 2 & $\begin{array}{l}\text { Wind speed } \\
0-2 \mathrm{~m} \mathrm{~s}^{-1}\end{array}$ & $\begin{array}{l}\text { Wind speed } \\
2-5 \mathrm{~m} \mathrm{~s}^{-1}\end{array}$ \\
\hline 1 & 270 & & & 107 \\
\hline 2 & & 100 & & 136 \\
\hline 3 & 200 & & & 133 \\
\hline 4 & & 135 & 189 & \\
\hline 5 & 350 & & 390 & \\
\hline 6 & & 200 & 330 & \\
\hline 7 & 320 & & - & - \\
\hline Average & 285 & 145 & 303 & 126 \\
\hline SD & 57 & 41 & 103 & 16 \\
\hline
\end{tabular}

*Temperature readings between RISE and MHCLG are not comparable 
a wind speed varying between $0 \mathrm{~m} \mathrm{~s}^{-1}$ and $2 \mathrm{~m} \mathrm{~s}^{-1}$. The average time taken to reach $300^{\circ} \mathrm{C}$ for the windier condition is $42 \%$ of that for the stiller air condition. The first three Zagreb tests were not compliant with the BS 8414 limit, while the last three were compliant. RISE reported temperatures, measured using plate thermocouples $0.5 \mathrm{~m}$ in front of the top of the wood crib, rather than protruding from level 2, so direct comparison with MHCLG tests is not possible.

Other studies, using a propane burner as the fire source have shown the effect of wind both normal [33], and parallel $[34,35]$ to the façade to lessen the intensity of the thermal attack. In the case of a timber crib, wind will have a strong accelerating effect in the initial fire growth rate. Delichatsios [36] describes the classic model of façade flame height as needing revision. When a compartment undergoes transition to under-ventilated flaming, this reduces the temperature within the compartment but increases the temperature outside leading to more severe façade fires.

\subsection{Relative Location of Cavity Barriers and Thermocouples}

The UK government tests included 3 vertical cavity barriers [37], within a total façade width of $4 \mathrm{~m}$, shown in Fig. 2. The spacing of cavity barriers in a typical building - Grenfell Tower is used as an example - is shown alongside. According to $\mathrm{AD} \mathrm{B}$, the maximum distance between vertical cavity barriers is $20 \mathrm{~m}$ for products of lower reaction to fire classification; for Euroclass D materials and below, the separation is reduced to $10 \mathrm{~m}$. At the time of the test, the PIR, phenolic and ACM were all classified as Euroclass $\mathrm{C}$ or above, so the $20 \mathrm{~m}$ separation rule applies. In residential buildings, the cavity barriers would usually be located only at the property walls and floors between apartments, and around windows and other openings into the façade such as vent flues. Thus, there were twice as many vertical cavity barriers in the MHCLG sponsored tests than would be required by AD B, for a typical apartment of width of $8 \mathrm{~m}$. As well as the vertical cavity barriers, in the UK government tests, 4 horizontal barriers were installed at intervals of approximately $2.3 \mathrm{~m}$ within the $6.5 \mathrm{~m}$ façade section above the fire chamber.

The cavity barriers were of a higher specification in the UK government tests than the minimum recommended performance in $\mathrm{AD} \mathrm{B}$, i.e. fire resistance of $\mathrm{EI}$ 90/30 (provides $90 \mathrm{~min}$ integrity and $30 \mathrm{~min}$ insulation) for the vertical and horizontal cavity barriers, when AD B would only expect a fire resistance of EI 30/15 (30 min integrity and $15 \mathrm{~min}$ insulation) to be provided for cavity barriers. Thus, the fire-stopping capacity of the barriers used in the government test have three times longer integrity and twice the insulation time as those normally required.

BS 8414 defines a fixed position of the level 1 and level 2 thermocouples relative to the combustion chamber. The level 1 and level 2 thermocouples are respectively $2500 \mathrm{~mm}$ and $5000 \mathrm{~mm}$ above the top of the combustion chamber. This presents designers of BS 8414 test specimens with an unrealistic constraint because the thermocouple positions are not representative of a typical building geometry. Typical building geometries include floor-to-floor heights that are $\geq 3000 \mathrm{~mm}$ so the spacing between the level 1 and level 2 thermocouples is not the floor-to-floor height. The combustion chamber represents the position of a window opening, the 


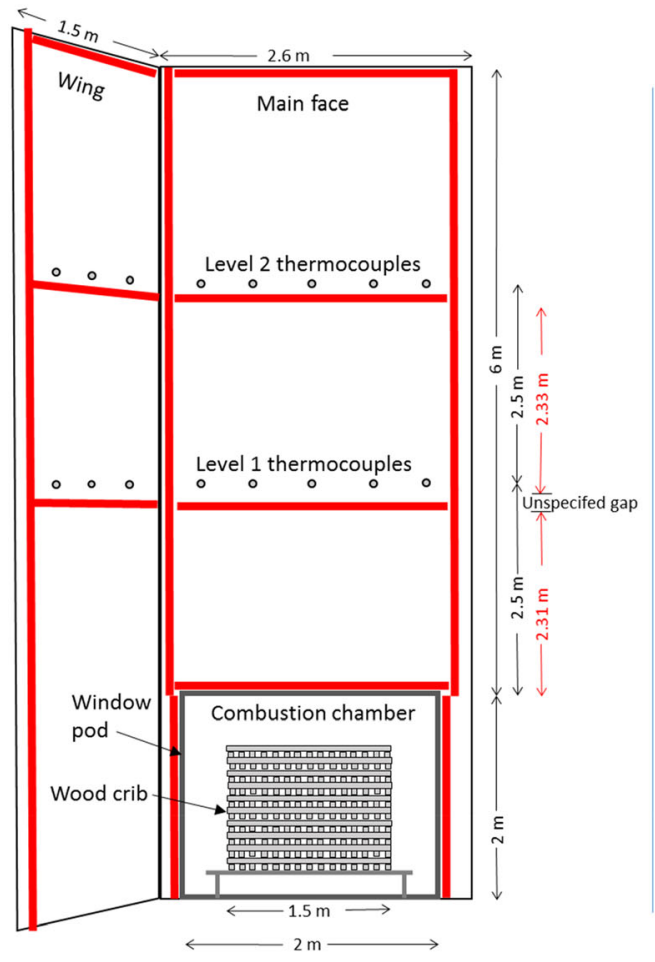

DCLG test

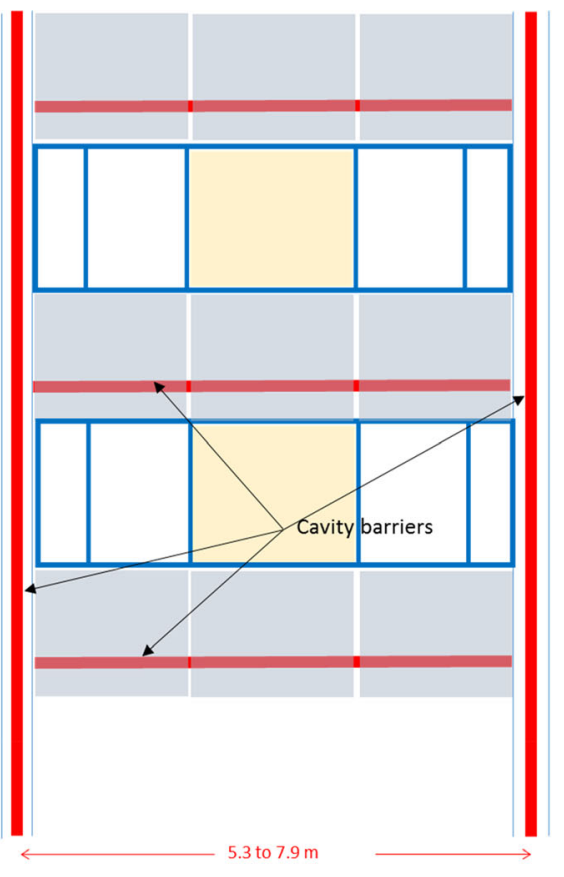

Grenfell Tower

\section{Figure 2. Cavity barriers shown in red in MHCLG tests [47], and on a typical building (Grenfell Tower is used as an example), drawn to approximately the same scale.}

distance from the top of a window opening on a typical building to the level of a floor above is usually 500 to $1000 \mathrm{~mm}$, significantly less than the $2500 \mathrm{~mm}$ separation to the level 1 thermocouples specified in BS 8414. For the level 1 thermocouples to be at the height of the floor above, with respect to the top of the combustion chamber (e.g. top of the window), would typically be less than $1000 \mathrm{~mm}$.

From the information presented in the reports, it appears that the level 2 cavity thermocouples were located just above the cavity barriers. In BS 8414-1, the level 2 thermocouple location is specified as $5000 \mathrm{~mm}$ above the combustion chamber, while the drawings show the $75 \mathrm{~mm}$ cavity barriers being located somewhere above $4660 \mathrm{~mm}$. Since the cavity barriers would normally be installed at floor level, to protect each apartment from fire spread from below, this represents an unrealistically small floor-to-floor height of $2330 \mathrm{~mm}$. The relative positions have been illustrated in Fig. 3. This will have the effect of helping to meet the BR 135 test criterion of reducing the temperature rise at the level 2 thermocouples (partic- 


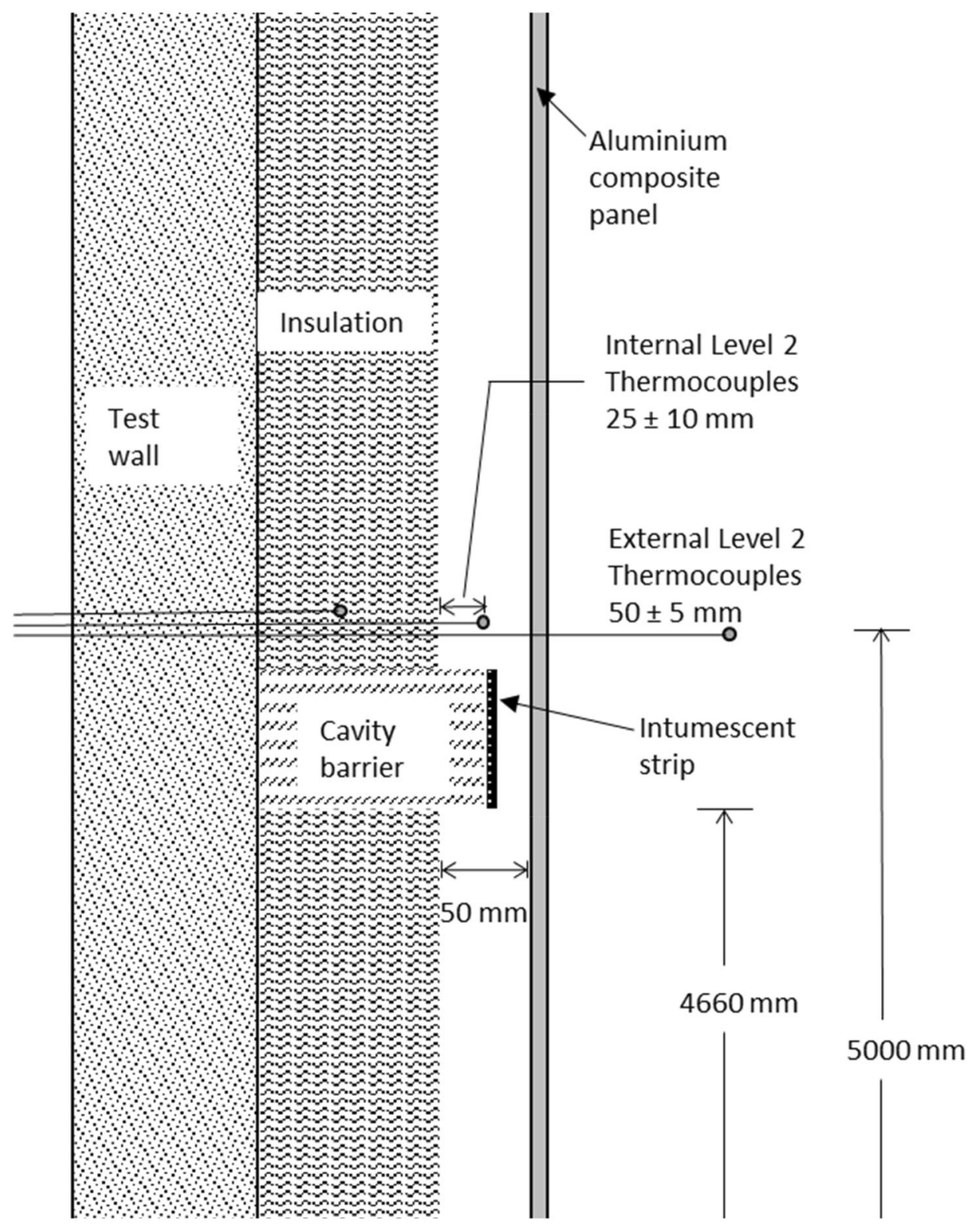

Figure 3. Relative positions of cavity barrier and level 2 thermocouples in the MHCLG tests.

ularly if the intumescent cavity barriers expand fully, as stated in the test reports), in such a way that would not exist in a real building. 


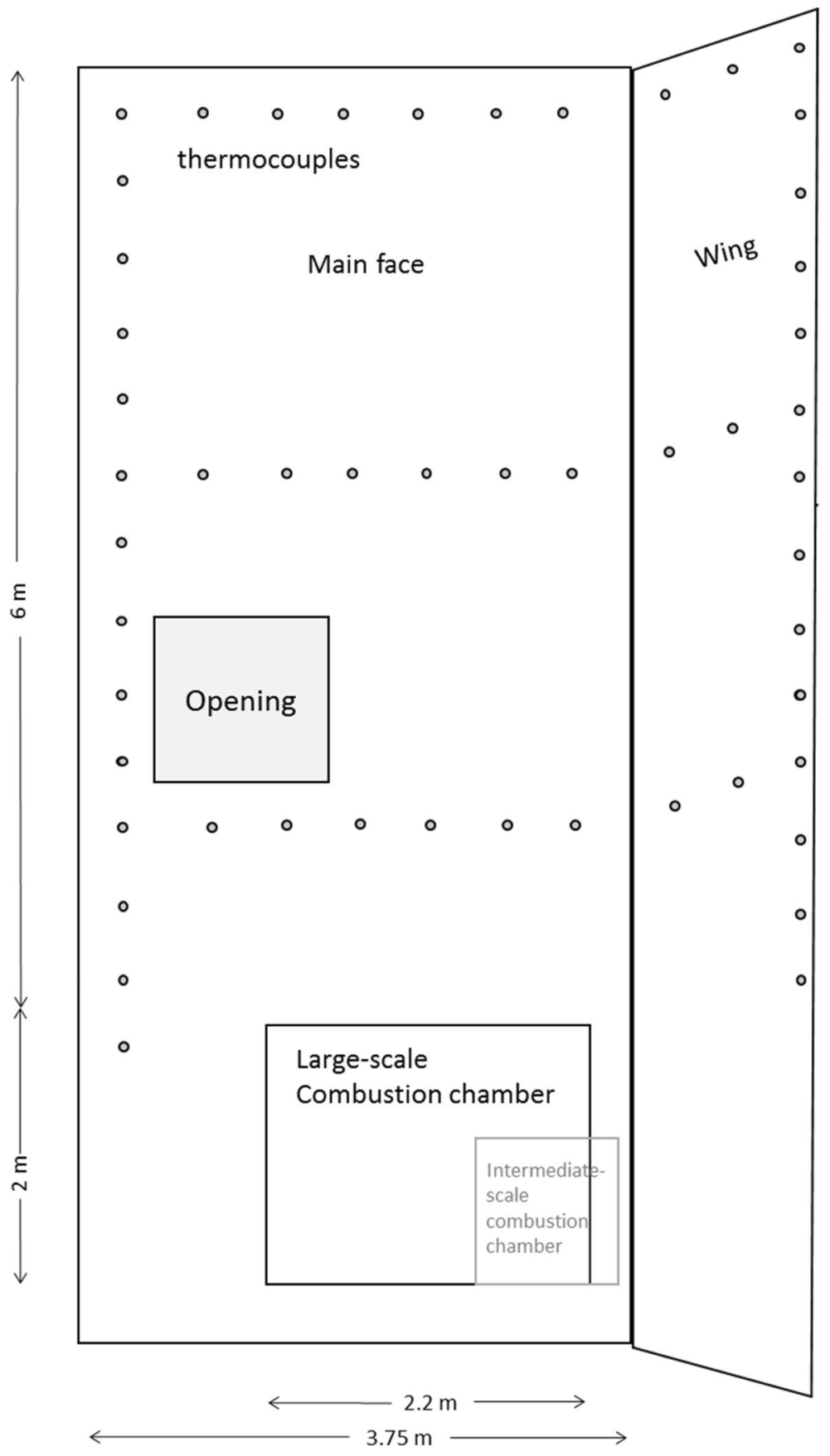

Figure 4. Alternative facade test apparałus, undergoing evaluation by European Commission. 


\section{Discussion}

The BS 8414 tests and the BR 135 criteria are the route by which combustible material is permitted on the external walls of tall buildings in the UK. This paper has shown that this pass/fail approach in a single test does not provide the necessary assurances that meeting the test criteria will ensure fire safety. The role of the BS 8414 test in facilitating the use of combustible materials in high-rise buildings has been the subject of significant criticism following the Grenfell tragedy [38]. Professor Jose Torero, an expert witness to the Grenfell Tower Inquiry, has warned [39] that "many details can be hidden within the results of the test". "Tests such as BS 8414 provide a single scenario deemed consistent with an external fire, a very limited number of measurements and a very simple failure criterion. The combination of these three characteristics does not provide a sufficiently comprehensive assessment of performance." There are several parameters that are not adequately considered in the Standard, and the criteria for compliance with UK Building Regulations do not correspond to the performance requirement that "the external walls of the building shall adequately resist the spread of fire over the walls [...], having regard to the height, use and position of the building". Using the example of the seven tests sponsored by the MHCLG, it is clear that much more detail is necessary within BS 8414 to precisely specify the façade systems, so that their fire performance will be replicated on real buildings. The current BR 135 criteria do not ensure that any combustible components will have the capability to "adequately resist the spread of fire over the walls".

The current work highlights the ambiguities and lack of reproducibility of many aspects of the BS 8414 tests. In particular, it has been shown that it is possible to change the severity of the test conditions by careful adjustment of particular parameters, while still being compliant with the test protocol. The wood itself provides a significant source of irreproducibility, with the potential to halve the heat release from the burning crib by precise specification of the fuel. The greater fire growth rate, believed to result from differences in ventilation on BRE's test wall 2, located inside the burn hall, are a cause for concern. Effectively doubling the fire growth rate of the wood crib results in very different conditions for tests falling within the standard protocol, particularly if the threshold to a pass/fail is only counted within the first $15 \mathrm{~min}$. It has been suggested [22] that a constant heat output fuel source (probably a gas burner) would be far more effective in ensuring consistency of results, and would eliminate these two problems.

The use of an unrepresentatively large number of cavity barriers, or a heavyduty window pod are entirely permissible within the BS 8414 tests, but leaves significant untested vulnerabilities in real buildings. The relative positioning of thermocouples and cavity barriers needs to be explicitly stated. Fire growth within the cavity will be underestimated when the thermocouples are shielded by the cavity barrier. Flaming will be suppressed at the top of the rig if an additional unrepresentative cavity barrier is installed at its exit.

The failure criteria in BR 135 for the temperature rise on level 2 thermocouples exceeding $600^{\circ} \mathrm{C}$, for a period of at least $30 \mathrm{~s}$, within $15 \mathrm{~min}$ of the start of the test lack any scientific basis and are not adequate to ensure fire safety. It is hard 
to understand why the BR135 criteria do not make use of the temperatures at levels 1 and 2 for the full hour of the test. The rationale for, revised and more rigorous criteria, need to be made explicit so that designers can evaluate if and how these apply to their specific building configuration. Debris, molten and burning droplets falling from the fire scene must be reported in such a way that the risk assessor is fully aware of them; this should include photographs of the area below the test rig; records of the debris composition (mass and size); and a description in the timeline of when such events occur.

The methodology of the BS 8414 and the BR 135 criteria as an approval system for cladding on tall buildings excludes features found on typical buildings, such as windows, vents and other construction details that can enhance the spread of fire. Thus, to meet the UK Building Regulations, separate assessments of the effects of such detail on the overall fire performance should also be undertaken. In meeting the BR 135 criteria, only the fire performance of the façade system without windows or vents has been assessed.

\subsection{Insulation}

In many respects, the current BS 8414 test for rainscreen systems could be described as an assessment of the effectiveness of the cladding to protect the underlying combustible insulation. As early as 1986, a paper sponsored by the International Isocyanate Institute [40] recognised the dangers of rigid polyurethane insulation. Polyisocyanurate (PIR) is a rigid polyurethane based polymer which is enhanced by the formation of isocyanurate rings within its structure, by using an excess of isocyanate in the resin formulation, improving its fire performance. The former Technical Director of the PIR manufacturer, Celotex, described how PIR has changed over the last 20 years due to a price increase of the main raw material, isocyanate [41]. Early PIRs contained more than twice the ratio of isocyanate to polyol than the current products, which rely on flame retardants to pass the regulatory tests.

In the wake of the Grenfell Tower fire an industry sponsored initiative published results of tests using ISO 13785-1 [42]. The $100 \mathrm{~kW}$ burner did little more than penetrate the ACM, irrespective of whether it was filled with polyethene (PE), fire retarded polyethene, or non-combustible filling. For the ACM_PE, they reported that the insulants contributed little to the combustion, and this contribution probably stopped after destruction of the cladding. This simple set of tests has been used as the basis for modelling, and developed into a larger project used to justify a model of the Grenfell Tower fire $[43,44]$ in which the insulation made a negligible contribution to the flame spread. Another study has shown significant contributions from the burning insulation, in an estimate of the overall façade burning behaviour [45].

Professor José Torero, as an expert witness to the Grenfell Tower Inquiry, has specifically cited the risks of combustible insulation and the inadequacy of BS 8414 in accounting for those risks [39]. Professor Torero remarks, "A critical aspect that is missed by BS 8414 and observations is the burn-out of the insulation material $[\ldots]$ the insulation has the potential to burn for a much longer time 
period [than the cladding]. The duration of localized burning will be critical when defining the capacity of these fires to break back into the building". Professor Torero further observes that "the fire source, the focus on flame spread and duration of the test in BS 8414 all mask the role of the insulation and over emphasize the role of the rain-screen. None address the burn-out times and their role in sustaining localized burning'.

It is a matter of some concern that problems associated with the current test regime were absent from the test method proposed originally [23]. This brings into question the drivers behind, and motivation for, reducing the effectiveness of the standard. Given the understandable anger surrounding the Grenfell tragedy, there is a need to fully understand how these changes came about.

\section{Conclusions}

The process by which combustible façades are permitted on tall buildings in England does not ensure fire safety. In the light of the Grenfell Tower tragedy, discussion of a new and more robust approach is required. This paper is a contribution to that debate. It is limited in scope to the BS 8414 test standards, the criteria in Annex A of BR 135, and the MHCLG sponsored tests. It is clear that ambiguities within BS 8414 have created a test protocol which is far from reproducible, where potential changes from fail to pass can result from random variation or judicious optimisation of the experimental parameters. The criteria in BR 135 do not appear to align with any specific fire safety objectives, and cannot be considered to confer compliance with the UK Building Regulations. While the MHCLG tests are the first publicly available series of large scale façade fire tests, they were not sufficiently representative of the façades on buildings in the UK.

The clear and obvious short-term solution to the fire safety of façades problem is to prohibit the use of combustible materials on the exterior faces of tall buildings. The "combustibles ban" has achieved this for residential buildings constructed or renovated after February 2019. However, this leaves a large number of existing tall buildings, and a very large number of residential units, in an unfortunate position where they would not be compliant with current fire safety regulations. This has raised such serious concerns about the fire safety that it has resulted in mental trauma for occupants, and prevented the sale of apartments in tall buildings, because of the uncertainties around the fire safety status of their façades.

In order to re-establish public confidence and occupant safety, if large-scale tests were to continue to have a role in conferring compliance, it would first be necessary to further develop the large-scale test, so that it is more scientific, with demonstrable quantitative measurements and reproducibility, and its results evaluated against realistic acceptance criteria that help to designers and clients make informed decisions on fire safety. If it were considered expedient to revise the large-scale test methodology to quantify the fire threat from existing combustible facades, and if the BS 8414 test protocol were to be considered the most appropriate starting point, there are important areas that require further research and test- 
ing. These include the effects of differences between the design of the test specimens and the many design variables that occur in actual buildings, and the effects of differences in design and fabrication for a BS 8414 test, and construction practice in real buildings. Only when these effects have been properly quantified can the results of a BS 8414 test be of any value to ensuring the fire safety of a building.

In view of the continued lack of confidence in the current regulatory process, and the global interest in how the UK will address the problem of combustible façades, if the standard were to continue to exist in any form, it would also be necessary to address the following.

1. Fuel source The inconsistency associated with a fuel source whose heat release is not monitored or controlled leads to wide variation in test performance. Replacing the timber cribs with a regulated gas burner and heat flux meters on the facade would ensure that all facade tests were subject to the same thermal attack.

2. Test construction For the tests to be of value to façade and fire safety engineers, the precise details of the test specimen construction must be available. These should be observed and recorded by the test laboratory and presented in the certification report. The relative position of cavity barriers and thermocouples must be clearly defined and aligned to specific fire safety objectives. The surrounding to the combustion chamber, intended to represent a post-flashover apartment, should have the window surround that would be used in the actual construction, not a heavy-duty aluminium pod.

3. Full-scale experimental investigation into the effects of different construction detailing between tests and real buildings Façade designers and specifiers need to know how details such as windows, interface details around windows, vents, breather membranes, façade fixings and cavity barrier positions will behave in a real fire. The incorporation of windows and vents into the BS 8414 test would significantly widen the assurance of fire safety provided by the test, and allow features such as windows and vents to be optimised to maximize fire safety.

4. Revised criteria The criteria in BR 135 need urgent revision to be aligned with specific fire safety objectives. With the exception of metals, such as aluminium or magnesium, there are probably no combustible construction products in common use with ignition temperatures exceeding $600^{\circ} \mathrm{C}$. The current criteria would allow all combustible materials to ignite within $15 \mathrm{~min}, 5 \mathrm{~m}$ above the flashover apartment and still be compliant. This is inconsistent with any conservative fire safety objective. If the temperature was kept below $400^{\circ} \mathrm{C}$ for $60 \mathrm{~min}$, below the cavity barrier, there may be a reasonable expectation that the façade would be effective in suppressing vertical fire spread for many construction products of lower flammability. Given the diversity of high-rise buildings, from offices and luxury accommodation to social housing, care homes and hospitals, instituting a range of performance criteria, of increasing fire safety, rather than a single pass/fail result would give designers and engineers 
more information on uncertainty and risk, and regulators more scope to deliver the highest levels of fire safety to the most vulnerable. Detailed reports of falling debris must be included in the final classification report and made publicly available. Architects, fire safety engineers and fire and rescue services all need detailed warnings of the potential for falling debris to protect personnel and ensure safe evacuation.

5. Public access to information about passed and failed tests There is currently no obligation for test sponsors or test laboratories to publish any information about tests that have not satisfied the performance criteria. Public access to this information is a crucial ingredient to improve awareness, trust and cultural attitudes in the industry. The very valuable recent study of façade fire test data [19] used data from a test laboratory in Poland (presumably because none was publicly available elsewhere). In her report to the Grenfell Tower Inquiry, Dr Lane observed [46] that

"The absence of a body of relevant fire test evidence for rainscreen cladding systems, and the components of rainscreen cladding systems, based on the current submissions to the Public Inquiry, show a serious failing in the testing and certification regime. A body of publicly available and relevant fire test evidence is urgently required to support common construction forms."

It is recongnised that test sponsors make significant investment in undertaking large scale testing, however, this should not present a barrier to establishing an appropriate mechanism for knowledge sharing which is in the interest of public safety.

\section{Open Access}

This article is licensed under a Creative Commons Attribution 4.0 International License, which permits use, sharing, adaptation, distribution and reproduction in any medium or format, as long as you give appropriate credit to the original author(s) and the source, provide a link to the Creative Commons licence, and indicate if changes were made. The images or other third party material in this article are included in the article's Creative Commons licence, unless indicated otherwise in a credit line to the material. If material is not included in the article's Creative Commons licence and your intended use is not permitted by statutory regulation or exceeds the permitted use, you will need to obtain permission directly from the copyright holder. To view a copy of this licence, visit http://creat ivecommons.org/licenses/by/4.0/.

\section{Appendix}

In view of the above conclusions it is worth noting that the "alternative" façade test proposal, currently under consideration by the European Commission (EC) addresses many of these concerns. The alternative proposal was included in a consortium report to the EC in June 2018, alongside the EC's preferred route of 


$\begin{aligned} & \text { Table } 3 \\
& \text { Summary of Classifications } \\
& \text { Facade Test [21 ] }\end{aligned}$
\begin{tabular}{llll} 
Classification & Scale of test & Maximum temperature rise & Falling parts/burning debris \\
\hline LS1 & Large & Pass & Fail \\
LS2 & Large & Pass & Pass \\
LS3 & Intermediate & Pass & Fail \\
LS4 & Intermediate & Pass & Pass \\
\hline
\end{tabular}

adopting the large-scale BS 8414 test for high-risk applications and the intermediate scale DIN 4102-20 test for lower fire safety classification. 18 of 28 member countries of the European Union favoured the alternative proposal and the EC have now launched a tender to undertake an interlaboratory reproducibility study (round-robin) on the alternative test method [13].

The alternative method has been described as a merger of BS 8414 and DIN 4102-20, but the proposal addresses many of the deficiencies in BS 8414. The proposed test rig, shown in Fig. 4 is $8.5 \mathrm{~m}$ tall and has interchangeable combustion chambers of $2.2 \mathrm{~m}$ (width) $2.0 \mathrm{~m}$ (height) x $1.0 \mathrm{~m}$ (depth) for the large-scale test, and $1 \mathrm{~m} \times 1 \mathrm{~m} \times 0.8 \mathrm{~m}$ for the intermediate-scale test. It also has a window opening, partly above the large-scale combustion chamber. It specifies that the details around the opening are representative of those used in practice for the system under test. The window opening is located so that it is partly, but not completely above the combustion chamber, to test the reaction to fire behaviour of the façade, and of the window detail. The proposal states that gas would be preferable as a fuel, but if wood is used, then the heat flux should be monitored using plate thermocouples above the combustion chamber, and at the secondary opening, and the mass loss rate of the wood crib should be investigated during the round-robin trial. If timber cribs are to be used, it is necessary to define the timber species, density, dimensional tolerances, finish (sawn or planed) and conditioning. It proposes a $3 \mathrm{MW}$ wood crib similar to that in BS 8414 for the large-scale test, extinguished after $30 \mathrm{~min}$, and a $30 \mathrm{~kg}$ fan-assisted wood crib for the intermediate scale test, extinguished after $22 \mathrm{~min}$. In both cases the test is terminated after $60 \mathrm{~min}$. Falling debris should be observed visually, in the absence of a suitable, more robust method for its quantification.

Four limited fire spread (LS) classifications have been proposed. LS1 and LS2 are based on BS 8414 and LS3 and LS4 are based on DIN 4102-20, and summarised in Table 3. The criteria for all the classifications are that no thermocouple should show a temperature rise greater than $500^{\circ} \mathrm{C}$, over the $60 \mathrm{~min}$ of the test. LS1 and LS3 have the additional criteria that there must be no falling debris (which is currently defined as less than: $1 \mathrm{~kg} ; 0.1 \mathrm{~m}^{2}$; or 10 burning drops). In general, the higher classification exempts testing for the lower classifications although LS2 will not exempt a test from LS3. The test report includes construc- 
tion detail and a description of the debris. However, it does not specify that the test report must be made publicly available.

Although this proposal has significant improvements on BS 8414 it still lacks a scientific basis, or input from the lessons learnt from the catastrophic facade fires of the last decade. For example, while the criteria of $500^{\circ} \mathrm{C}$ temperature rise of over the full $60 \mathrm{~min}$ of the test represent a fire safety improvement, the ignition temperature of most combustible materials is below $500^{\circ} \mathrm{C}$ and the strength of any aluminium support structures would be significantly reduced if a real facade were to reach this temperature. If items such as vents or breather membranes were present in the real building, but absent from the test, their influence on the fire performance of the actual façade would remain unquantified.

\section{References}

1. Professor Luke Bisby's expert report, Phase 1, Grenfell Tower Inquiry. https://www.gre nfelltowerinquiry.org.uk/evidence/professor-luke-bisbys-expert-report. Accessed 15 Nov 19

2. Grenfell Tower fire: Response and tackling fire risk in high rise blocks, House of Commons Library, BRIEFING PAPER Number 7993, 30 June 2017. http://researchbriefing s.parliament.uk/ResearchBriefing/Summary/CBP-7993

3. Ministry of Housing (2019) Communities and Local Government, Building Safety Programme: Monthly Data Release

4. Amendments to statutory guidance on assessments in lieu of test in Approved Document B (Fire Safety) - a consultation paper, Ministry of Housing, Communities and Local Government, HM Government, London, April 2018. https://assets.publishing.ser vice.gov.uk/government/uploads/system/uploads/attachment_data/file/698899/Desktop_ Studies_Consultation.pdf. Accessed 26 May 2020

5. Grenfell Tower Inquiry, Phase 1 Report, https://www.grenfelltowerinquiry.org.uk/phas e-1-report. Accessed 26 May 2020

6. Approved Document B: Fire Safety-Volume 1: Dwellings, (2019 edition), Building Regulations, HM Government, London. https://www.gov.uk/government/publications/fire-s afety-approved-document-b. Accessed 26 May 2020

7. Schartel B, Hull TR (2007) Application of cone calorimetry to the development of materials with improved fire performance. Fire Mater 31:327-354. https://doi.org/ 10.1002/fam.949

8. EN 13501-1:2018 Fire classification of construction products and building elements. Classification using data from reaction to fire tests, CEN, Brussels

9. Explanatory Memorandum To The Building (Amendment) Regulations 2018 No. 1230; http://www.legislation.gov.uk/uksi/2018/1230/pdfs/uksiem_20181230_en_002.pdf. Accessed 17 Nov 2019

10. BS 8414-1:2015 + A1:2017, Fire performance of external cladding systems - part 1: test method for non-load-bearing external cladding systems applied to the face of the building. BSI, London

11. BS 8414-2:2015 + A1:2017. Fire performance of external cladding systems. Test method for non-loadbearing external cladding systems fixed to and supported by a structural steel frame, BSI, London

12. Colwell S, Baker T (2013) BR 135: Fire Performance of external thermal insulation for walls of multistorey buildings. BRE Trust, Watford 
13. Finalisation of the European Approach to Assess the Fire Performance of Facades, 2019/S 179-434943, EU tender open to 8/11/2019 (16 h) https://ted.europa.eu/udl?uri= TED:NOTICE:434943-2019:TEXT:EN:HTML

14. Babrauskas V (1996) Façade fire tests: towards an international test standard. Fire Technol 32(3):219-230. https://doi.org/10.1007/BF01040215

15. Hu L, Milke JA, Merci B (2017) Special issue on fire safety of high-rise buildings. Fire Technol. https://doi.org/10.1007/s10694-016-0638-7

16. van Hees P, Hofmann A (2018) Editorial façade fire safety. Fire and Mater 42(5):465. https://doi.org/10.1002/fam.2663

17. Babrauskas V (2018) The grenfell tower fire and fire safety materials testing. https://ww w.fireengineering.com/articles/print/volume-171/issue-1/features/the-grenfell-tower-fire-a nd-fire-safety-materials-testing.html

18. Bonner M, Rein G (2018) Flammability and multi-objective performance of building façades: towards optimum design. Int J High Rise Build 7(4):363-374. https://doi.org/ 10.21022/IJHRB.2018.7.4.363

19. Bonner M, Wegrzynski W, Papis BK, Rein G (2019) KRESNIK: A top-down, statistical approach to understand the fire performance of building facades using standard test data, Build Environ (in press). https://doi.org/10.1016/j.buildenv.2019.106540

20. Construction Products Regulation, Internal Market, Industry, Entrepreneurship and SMEs, European Commission. https://ec.europa.eu/growth/sectors/construction/product -regulation_en

21. Development of a European approach to assess the fire performance of facades, European Commission, (2018). https://www.diva-portal.org/smash/get/diva2:1250881/FULL TEXT01.pdf

22. Anderson J, Boström L, McNamee R.J., Milovanović B (2016) Uncertainties in façade fire tests - measurements and modelling, MATEC Web of Conferences, 46, art. no. 03002

23. Investigation of the behaviour of external cladding systems in fire: Report on 10 fullscale fire tests, Fire Research Station Report CR143/94, April 1994

24. Acceptability of common wall constructions containing combustible materials in high rise buildings, NHBC Technical Guidance Note, July 2016

25. Fire test report: UK government BS 8414 test no.5, Ministry of Housing, Communities and Local Government, HM Government, London, August 2017. https://www.gov.uk/g overnment/publications/fire-test-report-dclg-bs-8414-test-no5. Accessed 14 Nov 2019

26. Fire Safety of Facades Report, RISE, Sweden, 2017. https://www.brandskyddsforeninge n.se/globalassets/brandforsk/brandforsk_rapport_300_151_brandkrav-pa-fasader.pdf

27. Taylor W (1983) Fire spread in concealed foamed plastic insulation. Fire Technol 19:192-203. https://doi.org/10.1007/BF02378699

28. Livkiss K, Husted BP, Beji T, van Hees P (2019) Numerical study of a fire-driven flow in a narrow cavity. Fire Saf J . https://doi.org/10.1016/j.firesaf.2019.102834

29. Walker RG (2017) PhD Thesis, University of Central Lancashire, UK

30. Fire test report: UK government BS 8414 test no.1, Ministry of Housing, Communities and Local Government, HM Government, London, August 2017. https://www.gov.uk/g overnment/publications/fire-test-report-UK government-bs-8414-test-no1

31. UK government fire test reports (2017): https://www.gov.uk/government/collections/gre nfell-tower\#fire-test-reports

32. Čolić A, Pečur IB (2020) Influence of horizontal and vertical barriers on fire development for ventilated façades. Fire Technol. https://doi.org/10.1007/s10694-020-00950-w

33. Ren F, Hu L, Sun X (2019) Experimental investigation on lateral temperature profile of window-ejected facade fire plume with ambient. Wind Fire Technol 55(3):903-913. https://doi.org/10.1007/s10694-018-0809-9 
34. Ren F, Zhang X, Hu L, Sun X (2019) An experimental study on the effect of fire growth in a lower-floor compartment on fire evolution and facade flame ejection from an upper-floor compartment. Proc Comb Inst 37(3):3909-3917. https://doi.org/10.1016/ j.proci.2018.07.014

35. Hu L, Sun X, Zhang X, Ren F (2019) Facade flame height and horizontal extending distance from opening of compartment fire with external sideward wind. Proc Comb Inst 37(3):3859-3867. https://doi.org/10.1016/j.proci.2018.06.201

36. Ren F, Hu L, Zhang X, Sun X, Zhang J, Delichatsios M (2019) Experimental study of transitional behavior of fully developed under-ventilated compartment fire and associated facade flame height evolution. Comb Flame 208:235-245. https://doi.org/10.1016/ j.combustflame.2019.07.003

37. Specific UK government fire test report 1 p.18. (2017). https://www.gov.uk/government/ uploads/system/uploads/attachment_data/file/648790/UKgovernmenttest2_BS_8414_Par t_1_test_report_Issue1.2.pdf

38. Dr Barbara Lane, Expert Witness Report. https://www.grenfelltowerinquiry.org.uk/evid ence/dr-barbara-lanes-expert-report. Accessed 25 Jun 2018

39. Expert Witness Report Phase 1 to Grenfell Tower Inquiry, Prof. Jose Torero: https://w ww.grenfelltowerinquiry.org.uk/evidence/professor-jose-l-toreros-expert-report. Accessed 25 Oct 2019

40. Jeffs GMF, Klingelhöfer HG, Prager FH, Rosteck H (1986) Fire-performance of a ventilated facade insulated with a B2-classified rigid polyurethane foam. Fire Mater 10(2):79-89. https://doi.org/10.1002/fam.810100206

41. Mitchener G (2018) Impact of Grenfell Tower fire disaster on polyisocyanurate industry. Polim Polym 63(10):716-722. https://doi.org/10.14314/polimery.2018.10.8

42. Guillaume E, Fateh T, Schillinger R, Chiva R, Ukleja S (2018) Study of fire behaviour of facade mock-ups equipped with aluminium composite material-based claddings, using intermediate-scale test method. Fire Mater 42(5):561-577. https://doi.org/10.1002/ fam. 2635

43. Dréan V, Girardin B, Guillaume E, Fateh T (2019) Numerical simulation of the fire behaviour of façade equipped with aluminium composite material-based claddingsmodel validation at intermediate scale. Fire Mater 43(7):839-856. https://doi.org/ $10.1002 /$ fam. 2745

44. Guillaume E, Drean V, Girardin B, Benameur P, Koohkan M, Fateh T (2019) Modelling Grenfell facade fire using multiscale experimental-numerical simulation method. In: Prooceedings of the International Conference of Fire Science and Technology (Interflam), pp 255-270,. Interscience Publications, London

45. McKenna ST, Jones N, Peck G, Dickens K, Pawelec W, Oradei S, Harris S, Stec AA, Hull TR (2019) Fire behaviour of modern façade materials - understanding the grenfell tower fire. J Hazard Mater 368:115-123. https://doi.org/10.1016/j.jhazmat.2018.12.077

46. Dr Barbara Lane, Expert Witness Report, https://www.grenfelltowerinquiry.org.uk/evid ence/dr-barbara-lanes-expert-report, paragraph 2.26.7, Accessed 25 Jun 2018

47. Specific UK government fire test report 2, p.28. (2017). https://www.gov.uk/governmen t/uploads/system/uploads/attachment_data/file/648790/UKgovernmenttest2_BS_8414_P art_1_test_report_Issue1.2.pdf

48. White N, Delichatsios M (2015) Fire hazards of exterior wall assemblies containing combustible components. Springer, New York

Publisher's Note Springer Nature remains neutral with regard to jurisdictional claims in published maps and institutional affiliations. 